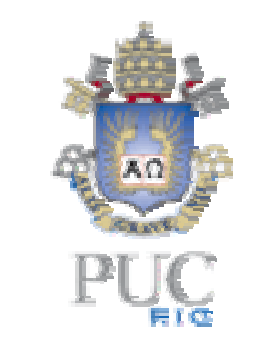

Diana Kelman Frajtag

\title{
Estrutura Organizacional de uma Agência Reguladora: Estudo de Caso
}

\begin{abstract}
Dissertação de Mestrado
Dissertação apresentada como requisito parcial para obtenção do grau de Mestre pelo Programa de Pósgraduação em Administração de Empresas do Departamento de Administração da PUC-Rio. Aprovada pela Comissão Examinadora abaixo assinada.
\end{abstract}

Orientador: Profa. Patrícia Amélia Tomei

Rio de Janeiro

Outubro de 2002 


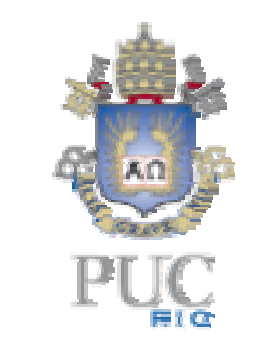

Diana Kelman Frajtag

\section{Estrutura Organizacional de uma Agência Reguladora: Estudo de Caso}

Dissertação apresentada como requisito parcial para obtenção do grau de Mestre pelo Programa de Pósgraduação em Administração de Empresas do Departamento de Administração da PUC-Rio. Aprovada pela Comissão Examinadora abaixo assinada.

Profa. Patrícia Amélia Tomei Orientadora Departamento de Administração, PUC-Rio

Prof. José Roberto Gomes da Silva Departamento de Administração, PUC-Rio

Profa. Úrsula Wetzel Coppead, UFRJ

Profa. Zélia M. de Lossio e Seiblitz Coordenadora Setorial do Centro de Ciências Sociais da PUC-Rio 
Todos os direitos são reservados. É proibida a reprodução total ou parcial do trabalho sem autorização da universidade, da autora e do orientador

\section{Diana Kelman Frajtag}

Graduou-se em Ciências Econômicas na FEA/UFRJ em 1993. Trabalha no HSBC na área de Private Banking.

Ficha Catalográfica

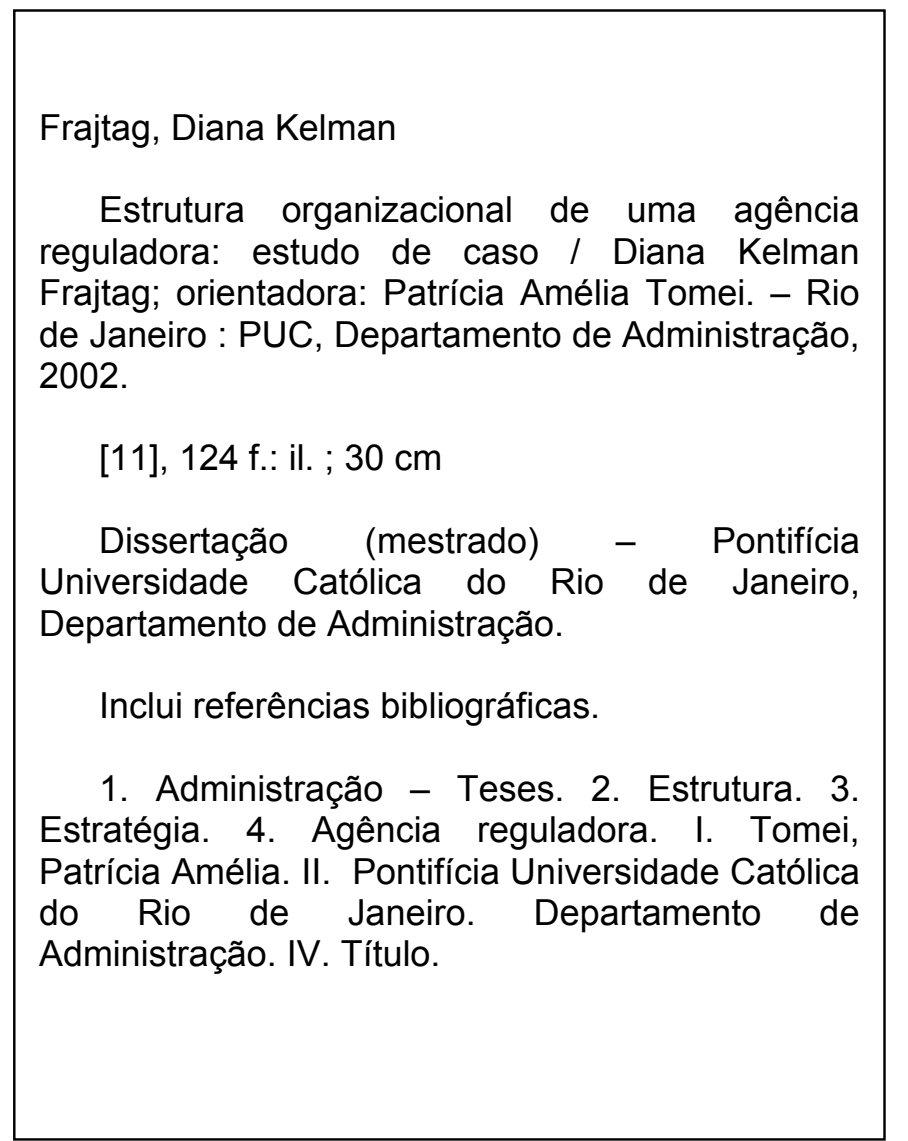

CDD: 658 


\section{Agradecimentos}

Ao meu filho, Alexandre, pelos carinhosos chutes dados dentro e fora da barriga, durante o decorrer da elaboração desta pesquisa.

Ao meu marido, Philippe, pelo amor, companheirismo e compreensão dedicados durante meu período de dupla gestação.

Ao meu pai, Jerson Kelman, diretor-presidente da ANA, pela tradicional dedicação ao meu trabalho e pelo empenho na defesa das nossas águas. A ANA é sua filha "temporã" e nasceu para possibilitar uma utilização racional dos rios, de modo que a água continue abundante para o Alexandre e para as próximas gerações.

A minha mãe, Celeste Azulay Kelman, pelo exemplo de mulher que é.

Aos funcionários da ANA, pelo auxílio e colaboração prestados durante esta pesquisa.

Aos amigos da PUC, pelo incentivo e apoio durante e após o curso de mestrado. 


\section{Resumo}

Frajtag, Diana Kelman;Tomei, Patrícia Amélia (orientadora). Estrutura Organizacional de uma Agência Reguladora: Estudo de Caso. Rio de Janeiro, 2002. 124p. Dissertação de Mestrado - Departamento de Administração, Pontifícia Universidade Católica do Rio de Janeiro.

O modelo de Mintzberg das cinco configurações estruturais é útil para a classificação das organizações e para a identificação de suas tendências evolutivas. O modelo serviu de suporte para uma análise crítica da estrutura adotada pela Agência Nacional de Águas - ANA. A ANA foi criada pela lei 9984/2000 com a missão de, simultaneamente, regular um bem de uso público - o uso dos rios - e implementar o Sistema Nacional de Gerenciamento de Recursos Hídricos. A ANA tem uma "dupla personalidade": deve atuar, ao mesmo tempo, como agência reguladora e implementadora. Com base em levantamento de documentos institucionais e legais e de pesquisa de campo, foram colhidos os dados necessários para : (i) identificar a missão e desenho funcional; (ii) verificar se a estrutura organizacional atendia às suas necessidades funcionais; (iii) analisar alternativas de arquitetura organizacional, à luz da teoria de Mintzberg. Concluiuse que a ANA ainda se encontra num estágio inicial de organização, semelhante à estrutura simples da taxonomia proposta por Mintzberg. Entretanto, constatou-se um acúmulo quantitativo de insuficiências nessa configuração inicial que prenunciam uma mudança qualitativa em direção a estruturas mais sofisticadas. Em particular, verificou-se que a missão da ANA seria melhor atendida se adotada a estrutura híbrida da "burocracia profissional" com a "adhocracia".

\section{Palavras-Chave}

Estrutura, estratégia, agência reguladora 


\section{Abstract}

Frajtag, Diana Kelman; Tomei, Patrícia Amélia (Advisor). Strucutral Organization of a Regulamentory Agency: Case Study. Rio de Janeiro, 2002. 124p. MSc.Dissertation - Departamento de Administração, Pontifícia Universidade Católica do Rio de Janeiro.

Mintzberg's five different structural configurations for organizations is a useful tool for both classifying and identifying evolutionary trends in organizations. His model was applied to make a critical analysis of the structure adopted by the Brazilian Water Authority - ANA. ANA was created by Law $9984 / 2000$ with the mission of regulate the use of a public resource - the water of the rivers - and to implement the National Water Resources Management Program. Thus, ANA has a "double personality" aspect and must act both as a regulatory agency and as policy maker for the Water Sector. Based on a compilation of institutional and legal documents and also on field research, important data was collected to: (i) identify ANA's mission and functional design; (ii) verify if the structural organization met the functional requirements; (iii) study alternatives for the organizational architecture, using Mintzberg's theory. It was found that ANA is currently in an initial organizational stage, similar to the simple structure of the taxonomy proposed by Mintzberg. However, a quantitative accumulation of deficiencies in this initial configuration has been observed, thus foreseeing a qualitative shift towards more sophisticated structures. In particular, it was observed that ANA's mission would be better met if a hybrid structure of "professional bureaucracy" and "adhocracy" was adopted.

\section{Keywords}

Structure, strategy, regulamentory agency 


\section{Sumário}

$\begin{array}{ll}\text { Lista de figuras } & 10\end{array}$

$\begin{array}{ll}\text { Lista de quadros } & 11\end{array}$

1 Introdução 12

1.1 O problema 12

$\begin{array}{lll}1.2 & \text { Objetivos do estudo } & 17\end{array}$

$\begin{array}{lll}1.3 & \text { Relevância do estudo } & 18\end{array}$

$\begin{array}{lll}1.4 & \text { Delimitação do estudo } & 19\end{array}$

2 O Papel das Agências Reguladoras na Administração Pública 21

2.1 New Managerialism: a nova administração pública 21

2.2 Autonomia e flexibilidade das agências reguladoras 26

2.3 Reforma do Aparelho do Estado e a Agência Nacional de Águas 27

3 Revisão Teórica 29

3.1 A visão estruturalista das organizações 29

3.2 O modelo de Mintzberg de configurações estruturais 43

3.2.1 Mecanismos de coordenação 43

3.2.2 As partes da organização 44

3.2.3 As formas da organização operar 48

3.2.4 Parâmetros delineadores 48

3.2.4.1Delineamento das posições individuais 49

3.2.4.2 Delineamento da superestrutura 51

3.2.4.3 Delineamento das ligações laterais 53 
3.2.4.4 Delineamento do sistema da tomada de decisão 56

3.2.4.5 Parâmetros delineadores e estruturação 58

3.2.5. As cinco configurações de Mintzberg 60

3.2.5.1 A Estrutura Simples 62

3.2.5.2 A Burocracia Mecanizada 64

3.2.5.3 A Burocracia Profissional 68

3.2.5.4 A Forma Divisionalizada 72

$\begin{array}{ll}\text { 3.2.5.5 A Adhocracia } & 78\end{array}$

$4 \quad$ Metodologia da Pesquisa $\quad 82$

4.1 Tipo de pesquisa $\quad 82$

4.1.1 Classificação quanto aos objetivos 82

4.1.2 Classificação quanto aos procedimentos técnicos adotados 83

4.1.2.1 Pesquisa bibliográfica 83

4.1.2.2 Pesquisa documental 83

4.1.2.3 Pesquisa de campo 84

4.1.2.4 Estudo de caso 84

4.2 Coleta de dados $\quad 85$

4.2.1 Pesquisa bibliográfica 86

4.2.2 Pesquisa documental 86

$\begin{array}{lll}\text { 4.2.3 Pesquisa de campo } & 86\end{array}$

$\begin{array}{lll}4.3 & \text { Tratamento dos dados } & 87\end{array}$

$\begin{array}{lll}4.4 & \text { Limitações do método } & 87\end{array}$

5 O Caso: A Agência Nacional de Águas 88

$\begin{array}{lll}5.1 & \text { Missão da ANA } & 92\end{array}$

$\begin{array}{lll}5.2 & \text { Estrutura da ANA } & 95\end{array}$

6 Resultados da Pesquisa: apresentação, interpretação e análise 105 
6.1 Manifestações dos dirigentes e funcionários sobre a estrutura da ANA

6.2 Mintzberg e a ANA

6.2.1 A Estrutura Simples e a ANA

6.2.2 A Burocracia Mecanizada e a ANA

6.2.3 A Burocracia Profissional e a ANA

6.2.4 A Forma Divisionalizada e a ANA

6.2.5 A Adhocracia e a ANA

7 Conclusões e Recomendações

7.1 Conclusões da pesquisa

7.2 Sugestões para futuras pesquisas

8 Referências Bibliográficas 


\section{Lista de figuras}

Fi gura 1 - Variáveis Básicas na Teoria Geral da Administração 30

Fi gura 2 - Teoria Estruturalista 34

Figura 3 - As Cinco Partes Básicas da Organização 44

Figura 4 - As Cinco Trações $\quad 60$

Figura 5 - Estrutura Simples $\quad 62$

Figura 6 - Burocracia Mecanizada 66

Figura 7 - Burocracia Profissional $\quad 69$

Figura 8 - Forma Divisionalizada $\quad 74$

$\begin{array}{ll}\text { Figura } 9 \text { - Adhocracia } & 79\end{array}$

Figura 10 - Exemplo de Bacia Hidrográfica 89

Figura 11 - Missão da ANA 94

$\begin{array}{ll}\text { Figura } 12 \text { - Organograma } & 102\end{array}$

Figura 13 - Organização da Bacia Hidrográfica 120 


\section{Lista de quadros}

Quadro 1 - Esquema Comparativo das Teorias da Administração 32

Quadro 2 - Tipologia de Blau e Scott 37

Quadro 3 - Tipologia de Etzioni 38

Quadro 4 - Parâmetros Delineadores de Mintzberg 49

Quadro 5 - As Cinco Configurações de Mintzberg 60

Quadro 6 - Estrutura Simples $\quad 62$

Quadro 7 - Burocracia Mecanizada 64

Quadro 8 - Burocracia Profissional 68

Quadro 9 - Forma Divisionalizada $\quad 72$

Quadro 10 - Adhocracia $\quad 78$

Quadro 11 - Parâmetros Delineadores e a ANA 127

Quadro 12 - Cinco Configurações de Mintzberg e a ANA 128 